\title{
On the modelling of ice-thickness redistribution
}

\author{
Jari HaAPALA \\ Department of Geophysics, P.O. Box 4 ( Fabianinkatu 24 A), University of Helsinki, FIN-00014 Helsinki, Finland
}

\begin{abstract}
An ice-thickness distribution model based on physical ice classes is formulated. Pack ice is subdivided into open water, two different types of undeformed ice, and rafted, rubble and ridged ice. Evolution equations for each ice class are formulated and a redistribution between the ice classes is calculated according to a functional form depending on the ice compactness, thickness and velocity divergence. The ice-thickness distribution model has been included in a coupled ice-ocean model, and numerical experiments have been carried out for a simulation of the Baltic Sea ice season. The extended ice classification allows separation of thermally and mechanically produced ice. Inherent thermodynamic growth/melting rates of the ice classes can be introduced into the model, giving a more detailed seasonal evolution of the pack ice. In addition, the model provides more information about the surface properties of pack ice.

Numerical experiments for the Baltic Sea show that both the sub-basin and inter-basin ice characteristics were realistically simulated by the model. Deformed-ice production was related to storm activity. Most of the deformation was produced in the coastal zone, which is also an important region for thermodynamically produced ice because of the ice growth in leads. The modelled mechanical growth rates of ice were $0.5-3 \mathrm{~cm} \mathrm{~d}^{-1}$ on a basin scale, close to the thermodynamic ice-production rates. The deformed-ice fraction was 0.2 in mid-winter and increased to $0.5-1.0$ during spring.
\end{abstract}

\section{INTRODUCTION}

The sea surface in polar regions is composed of open water, level ice and deformed ice. Undeformed ice is produced by the thermodynamic growth of sea ice as a result of the freezing of sea water. The dynamics of the ice pack is responsible for the production of deformed ice. During convergent ice motion, ice floes are compressed together, forming rafted, rubble and ridged ice, which are all types of deformed ice. On a geophysical scale the ice-thickness variability in a specific region is described by the ice-thickness distribution function (Thorndike and others, 1975). In addition to advection and thermodynamic growth, the evolution of ice-thickness distribution is due to production of deformed ice and open water. Production of deformed ice is called a redistribution of ice thickness, and this is the most problematic term in the evolution equation of the ice-thickness distribution. The physical behavior of sea ice is highly related to the icethickness distribution. It is known that the ice-velocity field depends on the ice-thickness distribution and vice versa, and previous model studies (Shinohara, 1990; Leppäranta and others, 1998; Arbetter and others, in press) suggest the need for a better description of ice thickness to improve dynamic ice-model simulations.

Ice strength, albedo, surface temperature and roughness are dependent on ice type (cf. Squire, 1998), and a detailed description of ice-surface characteristics is necessary for coupled models to calculate realistic fluxes of heat and momentum at the ocean-ice-atmosphere interface (Vihma, 1995). For example, the atmosphere-ice drag coefficient varies from $1.2 \times 10^{-3}$ (very smooth first-year ice) to $6.7 \times 10^{-3}$ (extremely rough multi-year ice (Guest and Davidson, 1991), and the ice- ocean drag coefficient varies from $1.0 \times 10^{-3}$ to
$34.8 \times 10^{-3}$ (Omstedt, 1998). Tremblay and Mysak (1997) and Steiner and others (1999) have shown that the ice thickness and roughness-related drag coefficient improve numerical simulations.

As simple a problem as the calculation of the total mass of sea ice cannot be solved accurately with either observational techniques or existing ice models alone, because of the uncertainties in determining the deformed-ice portion. The fraction of deformed ice has been estimated to be about one-third of the total ice mass in the Baltic (Lewis and others, 1993) and one-third to two-thirds in the Arctic (Flato and Hibler, 1995). Because of the critical importance of a proper description of the ice-thickness distribution in seaice modelling, Thorndike and others (1975) developed a general ice-thickness distribution theory, which was implemented in a pan-Arctic model by Hibler (1980). However, these contributions have not received much attention, and the two-level model of Hibler (1979) has become the most widely used sea-ice model. Gray and Morland (1994) and Gray and Killworth (1996) pointed out that the classic formulation of ice-thickness and -compactness evolution equations without any ridging terms leads to a physically unrealistic growth in ice area. Harder and Lemke (1994) extended the Hibler (1979) model to include evolution equations for ridged-ice thickness and compactness with ridging terms, and applied the model to the Weddell Sea, Antarctica. Flato and Hibler (1995) extended the general ice-thickness distribution theory of Thorndike and others (1975) to include ridged ice and modelled the Arctic pack ice. In that model it is assumed that a constant fraction (15-20\%) of the thinnest undeformed ice forms ridged ice. An important improvement made by the Flato and Hibler (1995) model is that the ice strength is taken as a function of the energy consumed for ridge genera- 
tion. Hibler (1980), Flato and Hibler (1995) and Arbetter and others (in press) have shown that an explicit calculation of deformed- and new-ice production improves the results of climate models of Arctic sea ice.

Leppäranta (1981a) distinguished between undeformed and deformed ice in a Baltic Sea ice forecasting model. The prognostic variables of the model were the level-ice thickness, ridge density, ridge sail height and total ice concentration. This scheme, with minor modifications, has been used in recent Baltic Sea ice models (Zhang and Leppäranta, 1995; Haapala and Leppäranta 1996; Schrum 1997). Some shortcomings of the Leppäranta (1981a) ice-redistribution scheme are that the model does not include separate equations for level-ice and deformed-ice concentrations, and that it assumes that ridging occurs only when ice concentration reaches unity during convergence.

This paper presents an ice-thickness distribution model based on physical ice classes. Gray and Morland's (1994) evolution equations for the ice concentration and thickness have been extended and an ice-thickness distribution model has been formulated where the pack ice is subdivided into open water, two different types of undeformed ice, and rafted, rubble and ridged ice. The ice-thickness distribution model has been included in a coupled ice--ocean model, and numerical experiments have been conducted which simulate Baltic Sea ice conditions.

\section{THEORY}

Pack ice contains open water and several different types of ice (Fig. 1). The ice-thickness variability in a region is a result of the ice motion and the varying age of the sea ice. Firstly, ice is classed as undeformed or deformed (WMO, 1970). Undeformed ice is generally called level ice and is subdivided according to its phase of development. In this paper, level ice refers to undeformed ice in general. The lead-ice class is used to describe new ice growth in fractures or leads. Subdivisions of the deformed ice are rafted ice, rubble ice (or hummocked ice) and ridged ice (WMO, 1970). The

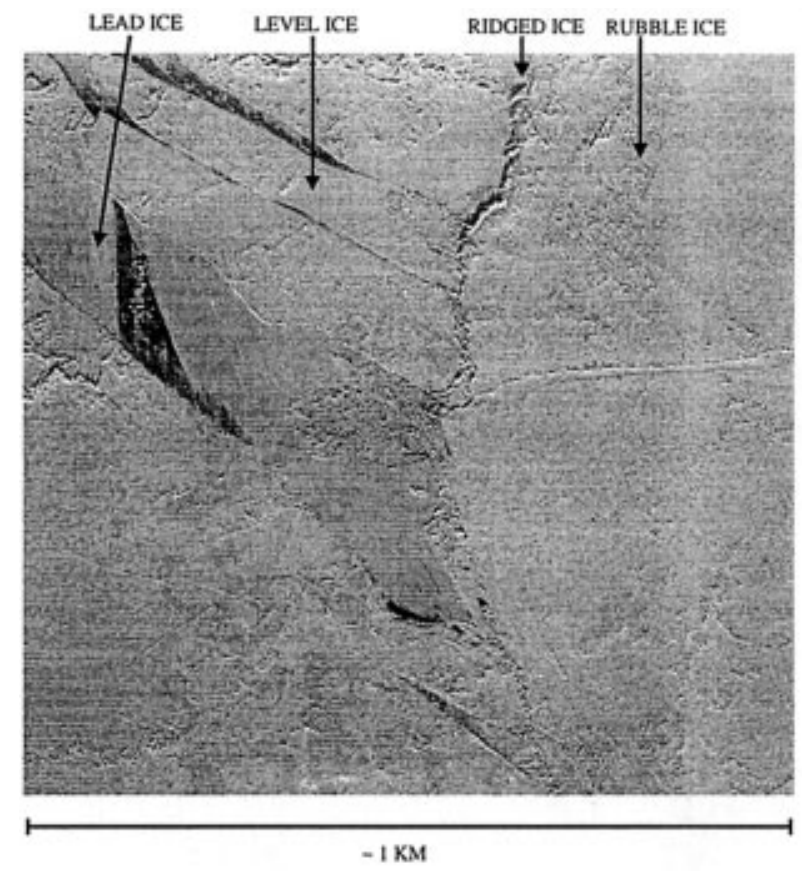

Fig. 1. Aerial photo of a deformed-ice field in the Bay of Bothnia, March 1994 (courtesy of the Swedish National Defence Research Establishment). deformed-ice types are produced when the ice field experiences convergent motion. If the ice is thin enough, it forms rafted ice, i.e. ice floes partly override each other. Ridges are stripe-like formations produced by pressure between colliding ice floes. In the Baltic, the heights of the ridges are typically 5-15 m, and the maximum thickness is about $30 \mathrm{~m}$ (Palosuo, 1974; Kankaanpää, 1991; Leppäranta and Hakala, 1992). Rubble fields are a conglomeration of small ice pieces oriented randomly but forming a fairly constant-thickness layer of ice. This layer is frozen together after an ice field breaks up into pieces with a diameter of the order of $1 \mathrm{~m}$ which are then pushed together by the ice pressure. Very few data are found in the literature about the formation and the detailed morphological characteristics of rubble fields. Parmeter (1975) and Hopkins (1998) suggested that the rubble fields are an extension of ridged ice and rubble and are created after ridge formation for as long as convergent motion continues and there is any undeformed ice left. The present model cannot take account of such a process, so a crude approximation of the generation of rubble fields is made in this study. We assume that the rubble fields are formed from lead ice which is neither thick enough to form a ridge nor thin enough for rafting.

Gray and Morland (1994) derived evolution equations for ice concentration and thickness which explicitly state that local changes of ice compactness and thickness are due to advection, redistribution of mass and the thermodynamic growth or decay of the ice cover. An alternative derivation is presented by Shinohara (1990) and Schulkes (1995). The formulae are

$$
\begin{aligned}
\frac{\mathrm{D} A}{\mathrm{D} t}+(1-r) A \operatorname{div} \vec{u} & =\Theta^{A} \\
\frac{\mathrm{D} h}{\mathrm{D} t}+r h \operatorname{div} \vec{u} & =\Theta^{h},
\end{aligned}
$$

where $A$ is the ice compactness, $h$ is the mean ice-floe thickness, $r$ is the ice-thickness redistribution function, $\operatorname{div} \vec{u}$ is the divergence of the horizontal ice-velocity field, and $\Theta^{A}$ and $\Theta^{h}$ are the thermodynamic growth rates of the ice compactness and thickness, respectively. These equations are reduced to the same evolution equations as those solved in the Leppäranta (1981a) model by choosing the redistribution function to be unity during convergent ice motion for compact pack ice. In other conditions, the function is zero.

In addition to direct discretization of the ice-thickness distribution (Thorndike and others, 1975; Flato and Hibler, 1995; Arbetter and others, in press), the ice-thickness distribution can be approximated with a model based on ice classes. The primary classification is a separation of the ice mass into an undeformed and a deformed part (Leppäranta, 1981a; Harder and Lemke, 1994; Haapala and Leppäranta, 1996). In this paper, undeformed ice is further separated into two classes called level ice $\left(A_{\mathrm{l}}, h_{\mathrm{l}}\right)$ and lead ice $\left(A_{\mathrm{le}}, h_{\mathrm{le}}\right)$. Deformed ice is classified as rafted ice $\left(A_{\mathrm{ra}}, h_{\mathrm{ra}}\right)$, rubble ice $\left(A_{\mathrm{ru}}, h_{\mathrm{ru}}\right)$ and ridged ice $\left(A_{\mathrm{ri}}, h_{\mathrm{ri}}\right)$. Formally,

$A=A_{\mathrm{l}}+A_{\mathrm{le}}+A_{\mathrm{ra}}+A_{\mathrm{ru}}+A_{\mathrm{ri}}$

$h=\left(A_{l} h_{\mathrm{l}}+A_{\mathrm{le}} h_{\mathrm{le}}+A_{\mathrm{ra}} h_{\mathrm{ra}}+A_{\mathrm{ru}} h_{\mathrm{ru}}+A_{\mathrm{ri}} h_{\mathrm{ri}}\right) / A$.

Note that the mean ice thickness per unit area is $\tilde{h}=A h$, and the mean level-ice thickness per unit area is $\tilde{h}_{\mathrm{l}}=A_{\mathrm{l}} h_{\mathrm{l}}$, etc.

The primary deformation mechanism is that the weakest ice class experiences deformations, i.e. level or lead ice is the source of deformed ice (Fig. 2). In addition, rafted ice can form double-rafted ice or ridges, but those mechanisms are neglected in this paper. Firstly, the ice-thickness redistribution function is 


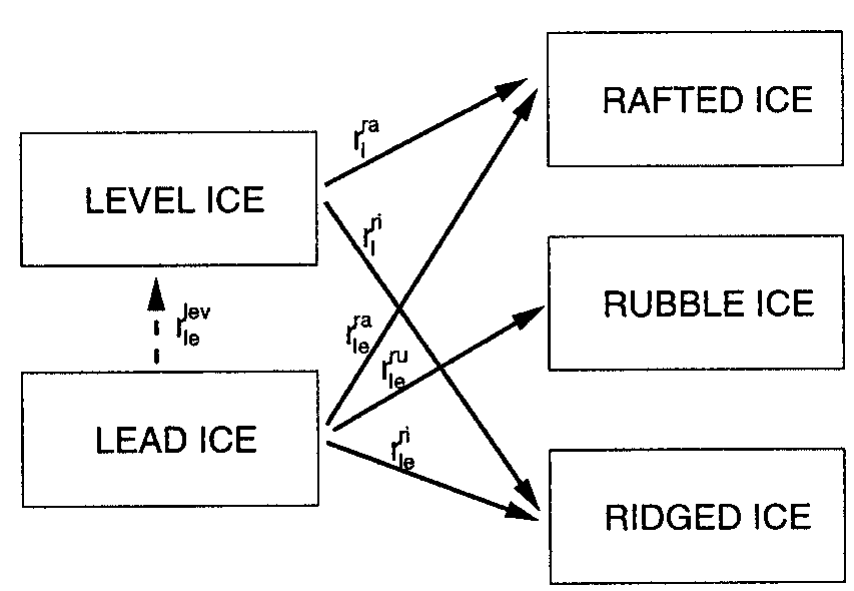

Fig. 2. Schematic figure of the ice-thickness redistribution of the ice classes. Solid lines indicate mechanical, and dashed line thermodynamic transformation processes of the ice mass described in the present work.

separated into the parts which denote the origin of the deformed ice,

$$
r=r_{1}+r_{\text {le }},
$$

where $r_{1}$ and $r_{\text {le }}$ are the redistribution functions of the level ice and lead ice, respectively. Redistribution functions are further separated into the parts which generate the rafted and the ridged ice. Rubble fields are generated only from the lead ice.

$$
\begin{aligned}
r_{\mathrm{l}} & =r_{\mathrm{l}}^{\mathrm{ra}}+r_{\mathrm{l}}^{\mathrm{ri}} \\
r_{\mathrm{le}} & =r_{\mathrm{le}}^{\mathrm{ra}}+r_{\mathrm{le}}^{\mathrm{ru}}+r_{\mathrm{le}}^{\mathrm{ri}} .
\end{aligned}
$$

\section{Evolution equations}

The evolution equations of the ice classes are based on Gray and Morland's (1994) equations, but mass flux due to redistribution occurs only from undeformed ice to deformed ice, i.e. redistribution of ice is a source of the deformed ice and a sink of the undeformed ice. The quantity of the mass flux depends on the deformation mechanism. Rubble and ridged ice are generated from an ice sheet, and the mass flux is directly proportional to undeformed ice thickness $\left(h_{\mathrm{u}} \operatorname{div} \vec{u}\right)$. The mass flux due to rafting is proportional to twice the thickness of undeformed ice $\left(2 h_{\mathrm{u}} \operatorname{div} \vec{u}\right)$ because the ice sheets are overriding during rafting. The equations for level ice are:

$$
\begin{aligned}
& \frac{\mathrm{D} A_{1}}{\mathrm{D} t}=-\left(1-r_{1}^{\mathrm{ra}}-r_{1}^{\mathrm{ri}}\right) A_{1} \operatorname{div} \vec{u}-r_{1}^{\mathrm{ra}} C_{\mathrm{ra}}-r_{1}^{\mathrm{ri}} C_{\mathrm{ri}}+\Theta_{1}^{A}(8) \\
& \frac{\mathrm{D} \tilde{h}_{1}}{\mathrm{D} t}=\left(2 r_{1}^{\mathrm{ra}}+r_{1}^{\mathrm{ri}}\right) h_{1} \operatorname{div} \vec{u}+A_{1} \Theta_{1}^{h}
\end{aligned}
$$

where tilde characters denote mean quantities per unit area. $C_{\text {ra }}$ and $C_{\text {ri }}$ are the rate of loss of level-ice concentration due to rafting and ridging. For the lead ice we have similar equations:

$$
\begin{aligned}
\frac{\mathrm{D} A_{\mathrm{le}}}{\mathrm{D} t}= & -\left(1-r_{\mathrm{le}}^{\mathrm{ra}}-r_{\mathrm{le}}^{\mathrm{ru}}-r_{\mathrm{le}}^{\mathrm{ri}}\right) A_{\mathrm{le}} \operatorname{div} \vec{u} \\
& -r_{\mathrm{le}}^{\mathrm{ra}} C_{\mathrm{ra}}-r_{\mathrm{le}}^{\mathrm{ru}} C_{\mathrm{ru}}-r_{\mathrm{le}}^{\mathrm{ri}} C_{\mathrm{ri}}+\Theta_{\mathrm{le}}^{A} \\
\frac{\mathrm{D} \tilde{h}_{\mathrm{le}}}{\mathrm{D} t}= & \left(2 r_{\mathrm{le}}^{\mathrm{ra}}+r_{\mathrm{le}}^{\mathrm{ru}}+r_{\mathrm{le}}^{\mathrm{ri}}\right) h_{\mathrm{le}} \operatorname{div} \vec{u}+A_{\mathrm{le}} \Theta_{\mathrm{le}}^{h} .
\end{aligned}
$$

$C_{\text {ru }}$ is the rate of loss of lead-ice concentration due to the formation of a rubble field. The principle of the above equations is that thermodynamically produced level and lead ice are the source of the deformed-ice mass. The first terms on the righthand side of the ice-concentration equations describe the compaction of the ice pack during convergence, and the other terms indicate the decrease in the undeformed-ice concentration due to deformation. The redistribution functions link the evolution equations of the deformed-ice classes to the evolution equations of the level and lead ice. Equations for the rafted ice are:

$$
\begin{aligned}
& \frac{\mathrm{D} A_{\mathrm{ra}}}{\mathrm{D} t}=\left(r_{\mathrm{l}}^{\mathrm{ra}}+r_{\mathrm{le}}^{\mathrm{ra}}\right) C_{\mathrm{ra}}+\Theta_{\mathrm{ra}}^{A} \\
& \frac{\mathrm{D} \tilde{h}_{\mathrm{ra}}}{\mathrm{D} t}=-2\left(r_{\mathrm{l}}^{\mathrm{ra}} h_{\mathrm{l}}+r_{\mathrm{le}}^{\mathrm{ra}}\right) h_{\mathrm{le}} \operatorname{div} \vec{u}+A_{\mathrm{ra}} \Theta_{\mathrm{ra}}^{h} .
\end{aligned}
$$

The deformed-ice classes are not expected to further redistribute to other deformed-ice classes, so there is no divergence term in the ice-compactness equations nor a mechanical sink term in the ice-thickness equation. Formulas for the rubble ice are:

$$
\begin{aligned}
& \frac{\mathrm{D} A_{\mathrm{ru}}}{\mathrm{D} t}=r_{\mathrm{le}}^{\mathrm{ru}} C_{\mathrm{ru}}+\Theta_{\mathrm{ru}}^{A} \\
& \frac{\mathrm{D} \tilde{h}_{\mathrm{ru}}}{\mathrm{D} t}=-r_{\mathrm{le}}^{\mathrm{ru}} h_{\mathrm{le}} \operatorname{div} \vec{u}+A_{\mathrm{ru}} \Theta_{\mathrm{ru}}^{h} .
\end{aligned}
$$

Finally, the equations for the ridged ice are:

$$
\begin{aligned}
& \frac{\mathrm{D} A_{\mathrm{ri}}}{\mathrm{D} t}=\left(r_{\mathrm{l}}^{\mathrm{ri}}+r_{\mathrm{le}}^{\mathrm{ri}}\right) C_{\mathrm{ri}}+\Theta_{\mathrm{ri}}^{A} \\
& \frac{\mathrm{D} \tilde{h}_{\mathrm{ri}}}{\mathrm{D} t}=-\left(r_{1}^{\mathrm{ri}} h_{\mathrm{l}}+r_{\mathrm{le}}^{\mathrm{ri}} h_{\mathrm{le}}\right) \operatorname{div} \vec{u}+A_{\mathrm{ri}} \Theta_{\mathrm{ri}}^{h} .
\end{aligned}
$$

The key problems in the above equations are to determine the redistribution and formation functions. The redistribution functions $r$ describe the intensity and type of deformed-ice production. The formation functions $C$ describe the growth rate of the deformed-ice area. Two essential constraints for the redistribution functions are that $\left(r_{1}+r_{\text {le }}\right) \rightarrow 1$ when $A \rightarrow 1$, and $\left(r_{1}+r_{\mathrm{le}}\right) \rightarrow 0$ when $A \rightarrow 0$.

\section{Redistribution functions}

Although there is no unequivocal relationship between the properties and deformations of the pack ice (Tuhkuri and Lensu, 1998; Hopkins and others, 1999) the following points are generally accepted: (i) deformations occur only during convergence; (ii) the rate of deformation depends on the ice compactness; and (iii) the type of deformation depends on the ice thickness. The first point is self-evident and can be handled by introducing the Heaviside function for horizontal divergence (Gray and Morland, 1994). The ice-compactness dependence is also clear, but an exact form of the function is not known. Harder and Lemke (1994) and Flato and Hibler (1995) used an exponential form similar to that in the icestrength equation of Hibler (1979), and that form is also used here. According to field observations, the type of the deformation depends on the undeformed ice-thickness. If the ice is thin, it forms rafted ice. The critical ice thickness for rafting $\left(h_{\text {cra }}\right)$ can be determined by the Parmeter (1975) law. On this basis we can formulate the redistribution functions ad hoc, where the ice-thickness dependence follows the logistic curve and the ice-compactness dependence follows the exponential form. The logistic curve is used because it is more suitable for numerical calculations than the numerically ill-behaved step 
function. The redistribution functions for level ice deformations are:

$$
\begin{aligned}
r_{\mathrm{l}}^{\mathrm{ra}}= & {\left[1-\left(1+h_{\mathrm{cra}} \mathrm{e}^{-B\left(h_{\mathrm{l}}-h_{\text {cra }}\right)}\right)^{-1 / h_{\text {cra }}}\right] } \\
& \cdot \mathrm{e}^{-C(1-A)} H(-\operatorname{div} \vec{u}) H\left(h_{\mathrm{l}}-h_{\mathrm{le}}\right) \\
r_{\mathrm{l}}^{\mathrm{ri}}= & \left(1+h_{\mathrm{cri}} \mathrm{e}^{-B\left(h_{1}-h_{\text {cri }}\right)}\right)^{-1 / h_{\text {cri }}} \\
& \cdot \mathrm{e}^{-C(1-A)} H(-\operatorname{div} \vec{u}) H\left(h_{\mathrm{l}}-h_{\mathrm{le}}\right),
\end{aligned}
$$

where $h_{\text {cri }}$ is critical thickness for ridging, assumed to be equal to $h_{\text {cra }}, B$ is a parameter which determines how quickly the redistribution function changes with the changing ice thickness, $C$ is the ice-compaction constant, $H(-\operatorname{div} \overrightarrow{\mathrm{u}})$ is the Heaviside function of divergence of the horizontal velocity field, and $H\left(h_{\mathrm{l}}-h_{\mathrm{le}}\right)$ is the Heaviside function for the thickness difference between the level and lead ice and determines whether the level or lead ice deforms.

For lead-ice deformation we have similar equations except that $H\left(h_{\mathrm{le}}-h_{\mathrm{l}}\right)$ takes the opposite form and we assume that the critical ice thickness for ridging is larger than $h_{\text {cra }}$. By this assumption rubble ice is formed when the undeformed-ice thickness range is $h_{\text {cra }}$ to $h_{\text {cri }}$. The redistribution functions for lead-ice deformations are:

$$
\begin{aligned}
r_{\mathrm{l}}^{\mathrm{ra}}= & {\left[1-\left(1+h_{\mathrm{cra}} \mathrm{e}^{-B\left(h_{\mathrm{l}}-h_{\text {cra }}\right)}\right)^{-1 / h_{\text {cra }}}\right] } \\
& \cdot \mathrm{e}^{-C(1-A)} H(-\operatorname{div} \vec{u}) H\left(h_{\mathrm{le}}-h_{\mathrm{l}}\right) \\
r_{\mathrm{le}}^{\mathrm{ri}}= & \left(1+h_{\mathrm{cri}} \mathrm{e}^{-B\left(h_{\mathrm{l}}-h_{\mathrm{cri}}\right)}\right)^{-1 / h_{\mathrm{cri}}} \\
& \cdot \mathrm{e}^{-C(1-A)} H(-\operatorname{div} \vec{u}) H\left(h_{\mathrm{le}}-h_{\mathrm{l}}\right) \\
r_{\mathrm{le}}^{\mathrm{ru}}= & \left(\mathrm{e}^{-C\left(1-A_{\mathrm{l}}\right)}-r_{\mathrm{le}}^{\mathrm{ra}}-r_{\mathrm{le}}^{\mathrm{ri}}\right) H(-\operatorname{div} \vec{u}) H\left(h_{\mathrm{le}}-h_{\mathrm{l}}\right) .
\end{aligned}
$$

The above formulation states that only the thinnest undeformed ice experiences deformations. If both of the ice classes are expected to deform at the same time, the $H\left(h_{\mathrm{l}}-h_{\mathrm{le}}\right)$ function can be replaced by a function which shares deformation between the level and lead ice.

For the Baltic Sea, the Parmeter (1975) law gives $8 \mathrm{~cm}$ as the critical ice thickness for rafting (Leppäranta, 1981a). For lead-ice deformation, we assume that the minimum thickness for forming a ridge is $12 \mathrm{~cm}$. Figure 3 illustrates the dependence of the redistribution function on undeformed-

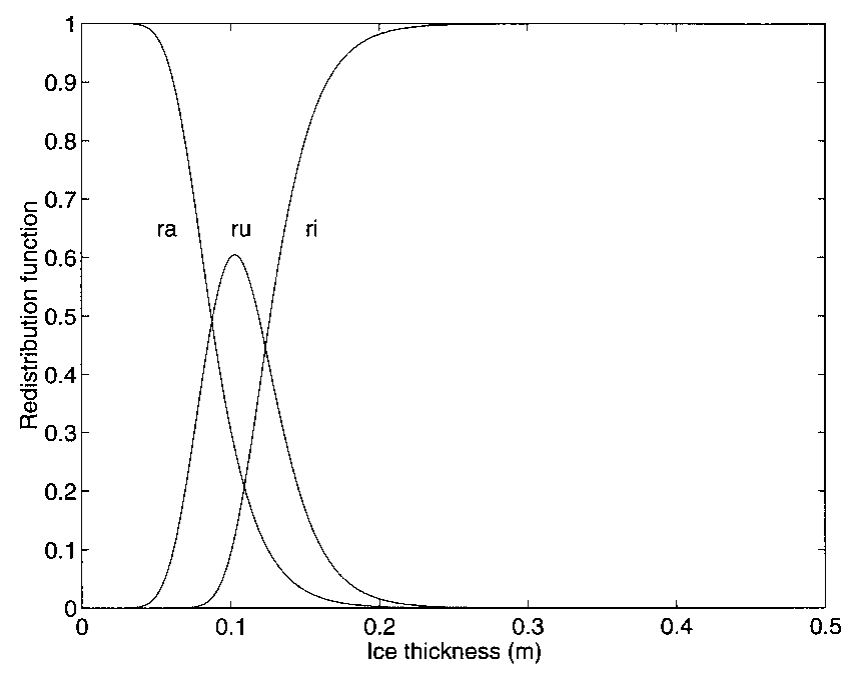

Fig. 3. Dependence of the redistribution functions for the rafting ( $\mathrm{ra}$ ), rubbling ( $\mathrm{ru}$ ) and ridging ( $\mathrm{ri}$ ) on the lead-ice thickness used in this study, $h_{\mathrm{cra}}=8 \mathrm{~cm}, h_{\mathrm{cri}}=12 \mathrm{~cm}$. ice thickness with these values. $B$ and $C$ are set at 50 and 20 , respectively.

In addition to the mechanical redistribution functions, a mass flux of ice between the ice classes results from thermodynamic growth of ice. In the present work the lead ice is redistributed to level ice using a linear function when the lead-ice thickness is $20-30 \mathrm{~cm}$ ( $r_{\text {le }}^{\text {lev }}$ in Fig. 2).

This approach does not take into account shear effects on the deformations. In the Arctic, shearing deformations contribute to the opening and closing of leads (Stern and others, 1995). Such observations are lacking in the Baltic, and the parameterization of the shear effects depends greatly on the scale and has uncertainties (Flato and Hibler, 1995). In a further development of the present model, the deformed-ice production due to shear is taken into account when appropriate field data are available.

\section{Formation functions}

The growth rate of the deformed-ice area depends on the shape and porosity of the deformed ice. If we assume that the horizontal divergence of the ice velocity is fully consumed by the vertical velocity needed for the deformations and deformed-ice thickness is constant, then according to the mass-conservation law, the growth rate of the deformed-ice area $C_{\mathrm{de}}$ for a rectangular-shaped ridge is generally in the following form:

$$
C_{\mathrm{de}}=-\frac{1}{(1-k)} \frac{\psi}{h_{\mathrm{d}}},
$$

where $\psi$ is the mass flux of ice from undeformed ice to deformed ice, $k$ is the porosity of the deformed ice, and $h_{\mathrm{d}}$ is the thickness of deformed ice. $k$ and $h_{\mathrm{d}}$ are unknown, and additional equations are needed to close the system. Several field observations have shown that the porosity of the deformed ice can be kept constant and the deformed-ice thickness is related to the undeformed-ice thickness (Kankaanpää, 1991; Timco and Burden, 1997).

The mass flux $\psi$ during the rafting is $2 h_{\mathrm{u}} \operatorname{div} \vec{u}$, the rafted ice thickness is $2 h_{\mathrm{u}}$ and its porosity is 0 . The growth rate of the rafted-ice area is simply reduced to:

$$
C_{\mathrm{ra}}=-\operatorname{div} \vec{u} \text {. }
$$

In the Baltic there are no measurements for the rubble ice, so we assume that the porosity of the rubble field is 0.3 , the same as for the ridges (Leppäranta and Hakala, 1992), and the thickness of the rubble is four times the undeformed-ice thickness. The mass flux is $h_{\mathrm{u}} \operatorname{div} \vec{u}$, so the growth rate of the rubble-ice area becomes

$$
C_{\mathrm{ru}}=-0.36 \operatorname{div} \vec{u} .
$$

We assume that the ridges are fully developed and their sizes follow a morphological model where the sail and keel heights are proportional to the undeformed-ice thickness (Timco and Burden, 1997). Observations from the Baltic suggest that ridge heights are rather constant in a length scale of $10 \mathrm{~km}$ (Leppäranta, 1981b; Lewis and others, 1993; Lensu, 1998), which implies that the ridges are regionally rather similar and their sizes are limited by the characteristic undeformed-ice thickness. An empirical fit to the Baltic Sea ridges gives the following relationship: $h_{\mathrm{d}}=17.64 h_{\mathrm{u}}^{0.5}$ (Kankaanpää, 1991). Equation (23) is derived for a rectangular-shaped ridge, but if we assume that ridges are triangular the equation must be multiplied by a factor 2. Furthermore, 
if the porosity of the ridges is 0.3 (Leppäranta and Hakala, 1992), the growth rate of the ridged ice area becomes

$$
C_{\mathrm{ri}}=-0.16 h_{\mathrm{u}}^{0.5} \operatorname{div} \vec{u} \text {. }
$$

\section{Momentum balance}

Using the ice-class approach has implications for the ice dynamics also. The momentum balance of the sea ice in a two-dimensional plane is:

$$
m\left(\frac{\mathrm{D} \vec{u}}{\mathrm{D} t}+f \hat{k} \times \vec{u}\right)=A\left(\vec{\tau}^{\mathrm{a}}+\vec{\tau}^{\mathrm{w}}\right)+m g \nabla H+\nabla \cdot \sigma,
$$

where $m$ is the total ice and snow mass, $\vec{u}$ is the horizontal ice-velocity vector, $f$ is the Coriolis parameter, $\hat{k}$ is the upward unit vector, $\vec{\tau}^{\mathrm{a}}$ is the air-stress vector, $\vec{\tau}^{\mathrm{w}}$ is the water-stress vector, $g$ is the gravitational acceleration, $H$ is the sea-surface tilt and $\sigma$ is the internal-stress tensor. When we know the areal fraction of the ice classes, we can separate air and water stresses between the undeformed-ice and the deformed-ice fractions. This is particularly important when the surface and ice internal stresses are low and the main forcing for the ice dynamics comes from the ocean stress.

$A \vec{\tau}^{\mathrm{a}}=\left(A_{\mathrm{l}}+A_{\mathrm{le}}+A_{\mathrm{ra}}\right) \vec{\tau}_{\mathrm{ud}}^{\mathrm{a}}+\left(A_{\mathrm{ru}}+A_{\mathrm{ri}}\right) \vec{\tau}_{\mathrm{de}}^{\mathrm{a}}$

$A \vec{\tau}^{\mathrm{w}}=\left(A_{\mathrm{l}}+A_{\mathrm{le}}+A_{\mathrm{ra}}\right) \vec{\tau}_{\mathrm{ud}}^{\mathrm{w}}+\left(A_{\mathrm{ru}}+A_{\mathrm{ri}}\right) \vec{\tau}_{\mathrm{de}}^{\mathrm{w}}$, where $\vec{\tau}_{\text {ud }}^{\mathrm{a}}$ and $\vec{\tau}_{\text {ud }}^{\mathrm{w}}$ are surface and bottom stresses representative of the undeformed ice (smooth surface) and $\vec{\tau}_{\text {de }}^{\text {a }}$ and $\vec{\tau}_{\text {de }}^{\mathrm{w}}$ are surface and bottom stresses of the deformed ice (rough surface). Note that rafted ice is included in the undeformed-ice portion because the rafted-ice surface acts as a smooth surface. If different drag coefficients for the rubble and ridged ice are known, the deformed-ice portion can be further separated.

\section{NUMERICAL EXPERIMENTS}

The numerical model is based on the Baltic Sea model described by Haapala and Leppäranta (1996). The model solves the momentum balance of sea ice, the ice-thickness redistribution and the thermodynamic growth and decay of ice and is coupled to a simple thermodynamic ocean-surface layer model (Haapala and Leppäranta, 1996). For the Baltic Sea ice simulations the momentum advection terms and the sea-surface slope effect are neglected in the momentum balance (Equation (27)). The internal stress of ice is calculated according to viscous-plastic rheology. The icestrength parameter is constant and and the momentum balance is solved by the overrelaxation method (Hibler, 1979). Thermodynamic growth and melting of ice is calculated according to the Semtner zero-level model (Semtner, 1976). All model parameters are the same as in Haapala and Leppäranta (1996). Equations (8-17) are calculated without the shear effects.

The size of the numerical grid is $10^{\prime}$ in latitude and $20^{\prime}$ in longitude, and the grid covers the whole Baltic Sea. The western boundary is closed at the Skagerrak $\left(9^{\circ} 30^{\prime} \mathrm{E}\right)$. Vertically the thermodynamics are solved in sigma coordinates. In these simulations four equally spaced levels were used $(0,0.33,0.66$, 1.0). The model topography is based on the Institut für Ostseeforschung (IOW) database (Seifert and Kayser, 1995).

The model is forced with fluxes of heat, moisture, radiation and momentum which were calculated from the Baltic
Sea meteorological database of the Swedish Meteorological and Hydrological Institute. The database includes air temperature, pressure, relative humidity, precipitation and geostrophic wind components interpolated into a $1^{\circ} \times 1^{\circ}$ grid over the Baltic Sea region. The time interval of the database is $3 \mathrm{~h}$. The surface wind was calculated from the geostrophic wind using mean values for the magnitude ratio and the ageostrophic turning angle which were 0.6 and 17, respectively (Bumke and others, 1998).

Atmosphere-ice and ice-ocean stresses were calculated according to Equations (28) and (29), and drag coeffients were based on the tables of Guest and Davidson (1991) and Omstedt (1998). For undeformed-ice types we used drag coefficients $1.2 \times 10^{-3}$ and $1.0 \times 10^{-3}$ for air-ice and ice-ocean stresses, respectively. Drag coefficients for deformed ice were $6.7 \times 10^{-3}$ and $34.8 \times 10^{-3}$. The parameterization methods of the surface heat and radiation fluxes are similar to those of Lehmann and Hinrichsen (2000). The initial conditions for the sea-water temperature and salinity were calculated from the 1961-90 climatology (Haapala and Alenius, 1994).

The model simulation was made for the ice season 1993/94. Three annual cycles were calculated before the actual simulation period in order to avoid the effect of initial conditions on the model results.

\section{MODEL RESULTS}

In this section we analyze when, where and how much deformed ice is produced by the model. Model results are compared to ice-chart information, satellite ice-concentration data and level-ice thickness observations. Deformed-ice thickness observations, such as sonar data, are not available.

The ice season 1993/94 was an average winter in the Baltic (Seinä and others, 1996). The initial freezing occurred in the northernmost areas at the end of October. The northern Bay of Bothnia and the eastern Gulf of Finland were ice-covered at the beginning of January. On 1 February the whole Bay of Bothnia and most of the Gulf of Finland were frozen. The annual maximum ice extent occurred on 3 March 1994, with the ice edge located around $59^{\circ} \mathrm{N}$. At that time, ice occupied $206 \times 10^{3} \mathrm{~km}^{2}(49 \%$ of the Baltic Sea area). Final ice disappearance occurred in the Gulf of Finland in early May and in the Bay of Bothnia at the end of May.

The model results show that the overall evolution of the ice season can be reproduced well. Modelled ice extent and the level-ice thickness (Fig. 4) follow fairly well the ice-chart information (FIMR, 1994), except that the model slightly overestimates the ice extent during the whole season.

Observed and modelled ice concentration and thickness in two locations, the Bay of Bothnia $\left(65^{\circ} 27^{\prime} \mathrm{N}, 23^{\circ} 33^{\prime} \mathrm{E}\right)$ and the Bothnian Sea $\left(62^{\circ} 47^{\prime} \mathrm{N}, 19^{\circ} 36^{\prime} \mathrm{E}\right)$, are shown in Figures 5 and 6. Observed ice concentration is based on Special Sensor Microwave/Imager (SSM/I) data (NSIDC, 1994), and ice thickness is based on the ice charts of the Finnish Institute of Marine Research (FIMR, 1994). The SSM/I observations clearly show the ice-covered period, but SSM/I data give rather low concentrations during mid-winter (0.7-0.9), much lower than those given in the ice charts (FIMR, 1994). This may be because very thin ice is interpreted as open water. The beginning and end of the ice season are fairly correctly modelled, but the model gives a higher ice concentration than the SSM/I data. The SSM/I data show large variations in ice concentrations due to dynamic and thermodynamic 

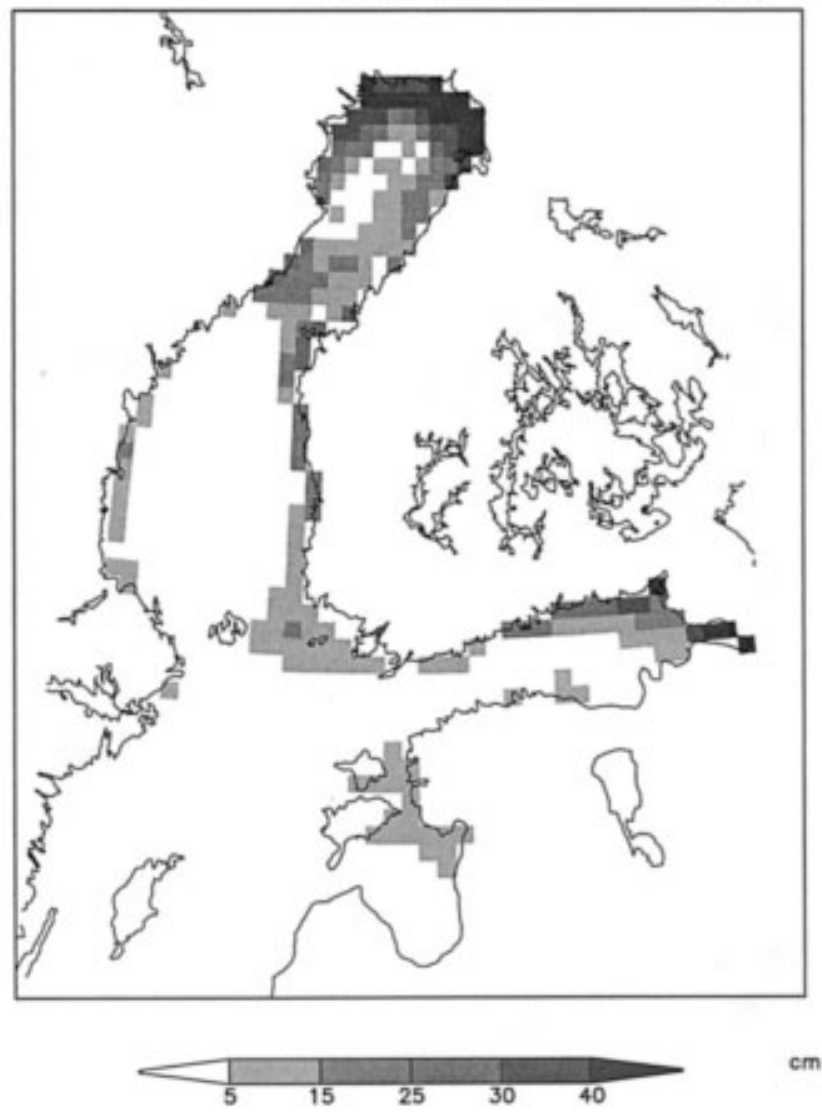

1 Mar 1994
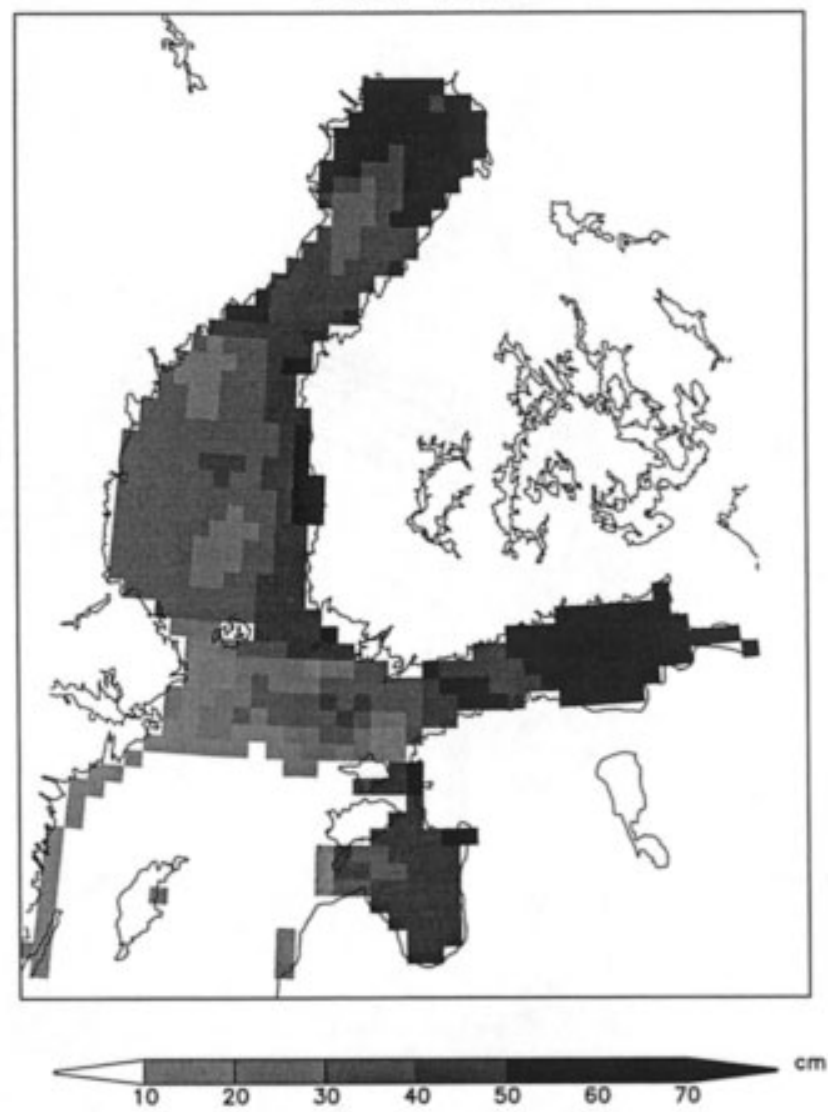
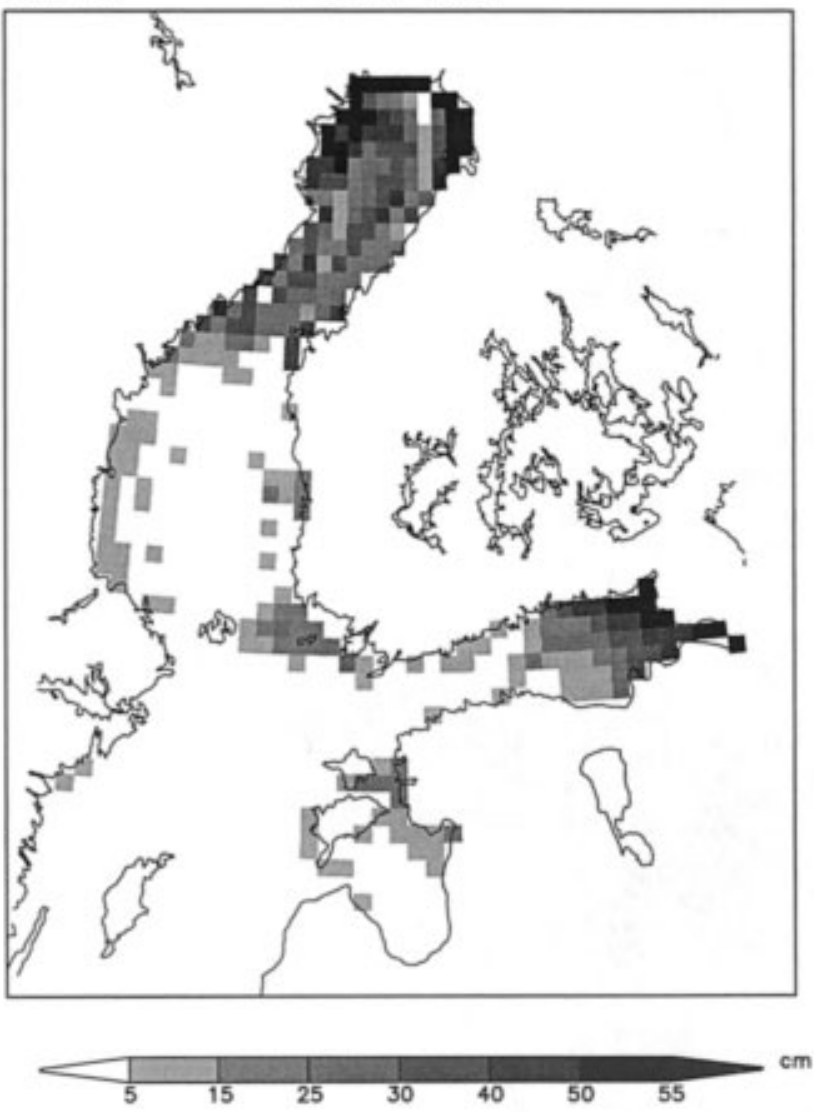

1 May 1994
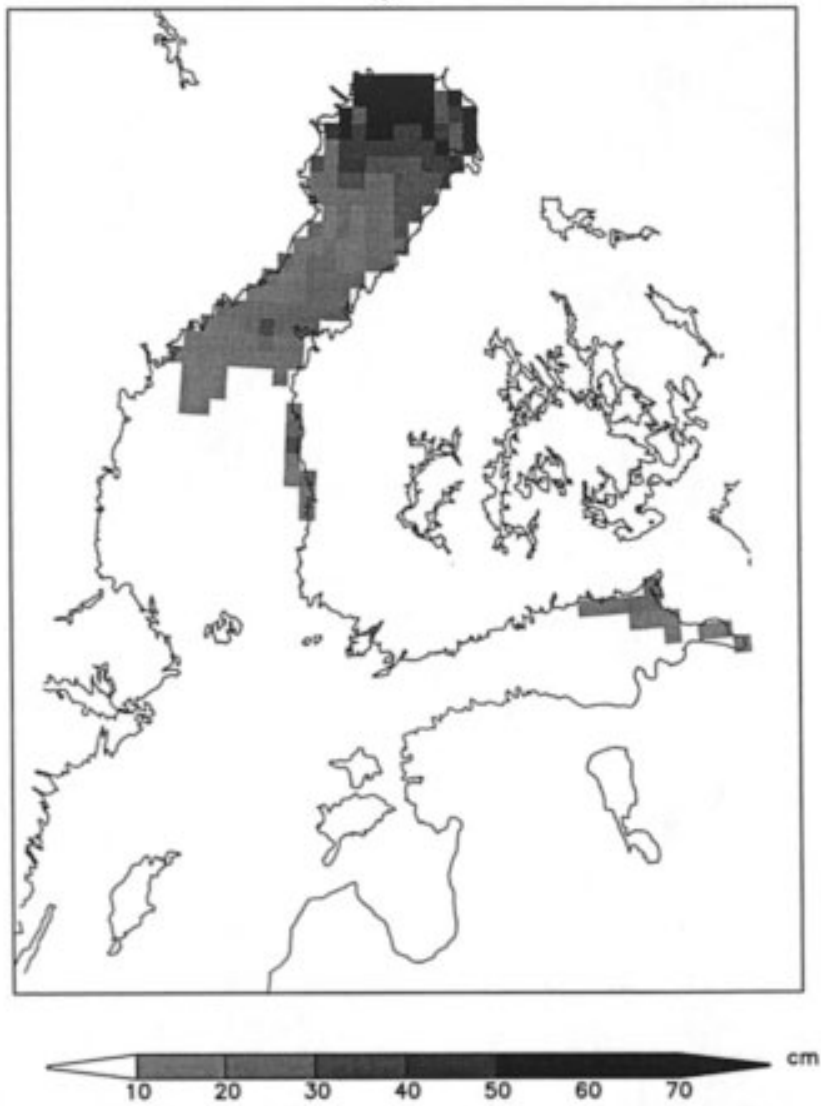

Fig. 4. Modelled mean level-ice thickness of 1 January, 1 February, 1 March and 1 May 1994.

effects, and some of these events are reproduced by the model at both the Bay of Bothnia and the Bothnian Sea sites. Especially good agreement is evident during the two episodes at the end of March and April. During mid-winter the model does not produce any open water as observations show, probably because ice conditions in the model are too immobile. In a relatively small basin like the Bay of Bothnia the viscous-plastic ice model tends to underestimate ice 
velocity or even have the ice remain stationary when mild or moderate winds are acting (Leppäranta and others, 1998). As a result, the modelled ice concentration at the Bay of Bothnia site is $>95 \%$ most of the time. During early winter and spring the lead-ice concentration increases occasionally up to $20 \%$. At the Bothian Sea site, representing more mobile ice conditions, the lead-ice concentration is $5-15 \%$ throughout the season.

The annual cycle of the level-ice thickness is rather well captured by the model (Figs 5 and 6). The difference between the ice-chart information and the modelled ice thickness is $\pm 10 \mathrm{~cm}$. The modelled ice-thickness time series show rapid changes due to redistribution and advection of the ice not evident from the ice-chart data. The ridged-ice thickness (mean thickness per unit area) shows a stepwise evolution. At the Bay of Bothnia site the ridged-ice thickness was about $5 \mathrm{~cm}$ during early winter and increased rapidly to $20 \mathrm{~cm}$ during a stormy period in early March. At the end of March the ridged-ice thickness was $30 \mathrm{~cm}$, or about half of the level-ice thickness. The ridged-ice thickness at the Bothnian Sea site varied from a few centimeters in mid-winter to $10 \mathrm{~cm}$ in spring (one-quarter of the level-ice thickness).

The above time series show the difference in ice conditions between the Baltic Sea sub-basins, but many details are also apparent at the basin scale. The observed ice condition during the annual maximum ice extent in winter 1994 is depicted in Figure 7a. Apparent ice conditions reflect the life history of the ice season. The Bay of Bothnia became ice-covered in mid-January, and the ridged- and rafted-ice region in the western sector of the basin was generated at the end of January (FIMR, 1994; Leppäranta and others, 1998). The Bothnian Sea became ice-covered in mid-February. At the end of February the westerly winds prevailed, and a lead generated on the western side of the basin and the eastern side experienced heavy deformations. Three classes of ice are clearly noticeable from the ice chart in the Bothnian

Bay of Bothnia
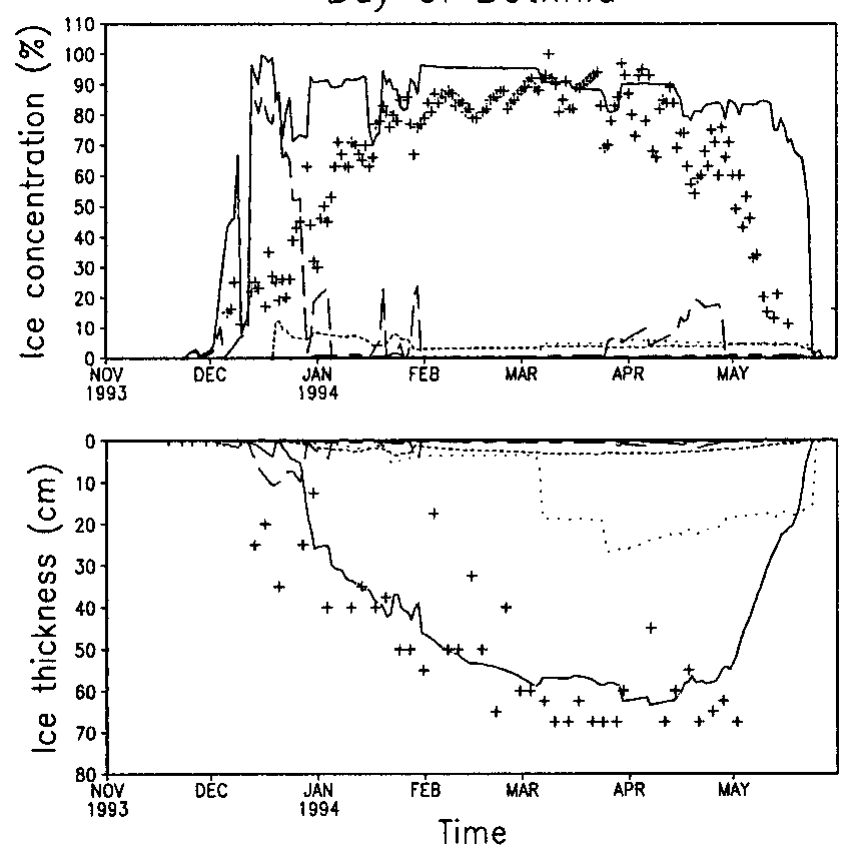

Fig. 5. Time series of observed and modelled mean ice thickness and concentration for the Bay of Bothnia. Crosses are observed values based on the SSM/I and ice-chart data, the solid line is the level ice, the dashed line the lead ice and the dotted line the ridgedice.
Sea (Fig. 7a): a zone of $10-20 \mathrm{~cm}$ thick lead ice on the western side, $10-25 \mathrm{~cm}$ thick rafted ice in the middle, and a ridged-ice region on the eastern side of the basin. The ridge areas are concentrated in the eastern and southern areas in the Gulf of Finland. Figure $7 \mathrm{~b}-\mathrm{d}$ present the modelled lead-, rafted- and ridged-ice mean thicknesses at the same date, and show that the observed features are apparent in the model results. The model-produced ice classes are located correctly, particularly in the Bothnian Sea, where the model produced lead ice on the western side, rafted ice in the middle and ridged ice on the eastern side of the basin. Regions of the modelled ridged-ice areas are located on the opposite coastal areas of the Bay of Bothnia and the Bothnian Sea. This indicates that the timing of the simulated deformed-ice production is also correct.

The ice-production rate for each ice class integrated over the Bay of Bothnia shown in Figure 8 reveals much about the thermodynamics and deformation processes of the ice pack. Positive ice-production rates for the level and lead ice indicate thermodynamic growth of ice. Negative production rates indicate melting or the redistribution of undeformed ice, with redistribution yielding positive production rates for rafted, rubble or ridged ice. Negative production rates for the deformed-ice classes indicate simply melting of the ice. The maximum thermodynamic growth rate of level ice is $5-6 \mathrm{~cm} \mathrm{~d}^{-1}$. The lead-ice production rate is less, about $1-2$ $\mathrm{cm} \mathrm{d}^{-1}$, because the lead-ice production is integrated over the whole basin. Locally it exceeds $5 \mathrm{~cm} \mathrm{~d}^{-1}$. Deformed-ice production is a stepwise process because it occurs mainly during stormy periods. Rafted and rubble ice are produced mostly during early winter. As the undeformed ice thickens, the ridged-ice production dominates deformed-ice production. The average ridged-ice production rate during ridging events is about $0.5 \mathrm{~cm} \mathrm{~d}^{-1}$. The maximum deformed-ice production rate is $3.5 \mathrm{~cm} \mathrm{~d}^{-1}$, close to the maximum thermodynamic growth rates. The production rate of rafted ice occasionally reaches $0.2 \mathrm{~cm} \mathrm{~d}^{-1}$ but most of the time is $<0.1 \mathrm{~cm} \mathrm{~d}^{-1}$. The rubble-ice production rate is only about one-tenth of the
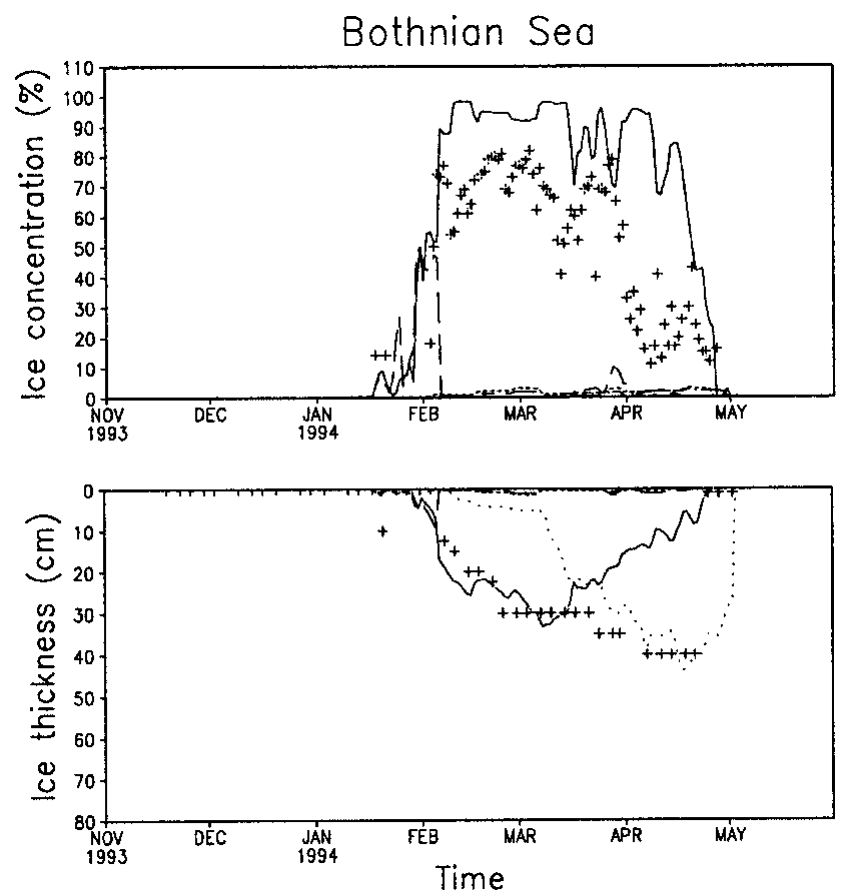

Fig. 6. Time series of observed and modelled mean ice thickness and concentration for the Bothnian Sea. The symbols are as in Figure 5. 

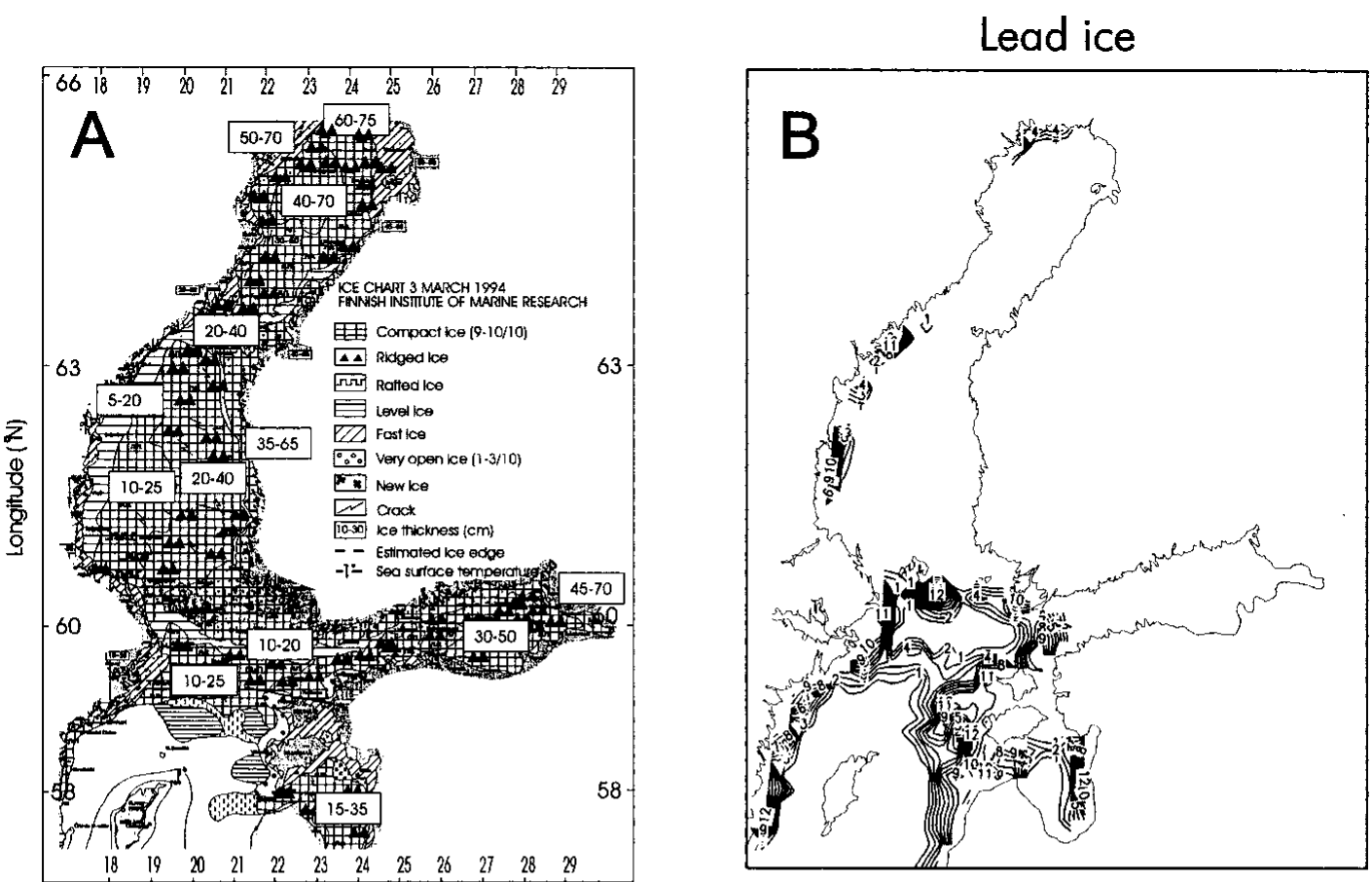

Latitude ( ${ }^{\mathrm{E}}$ )
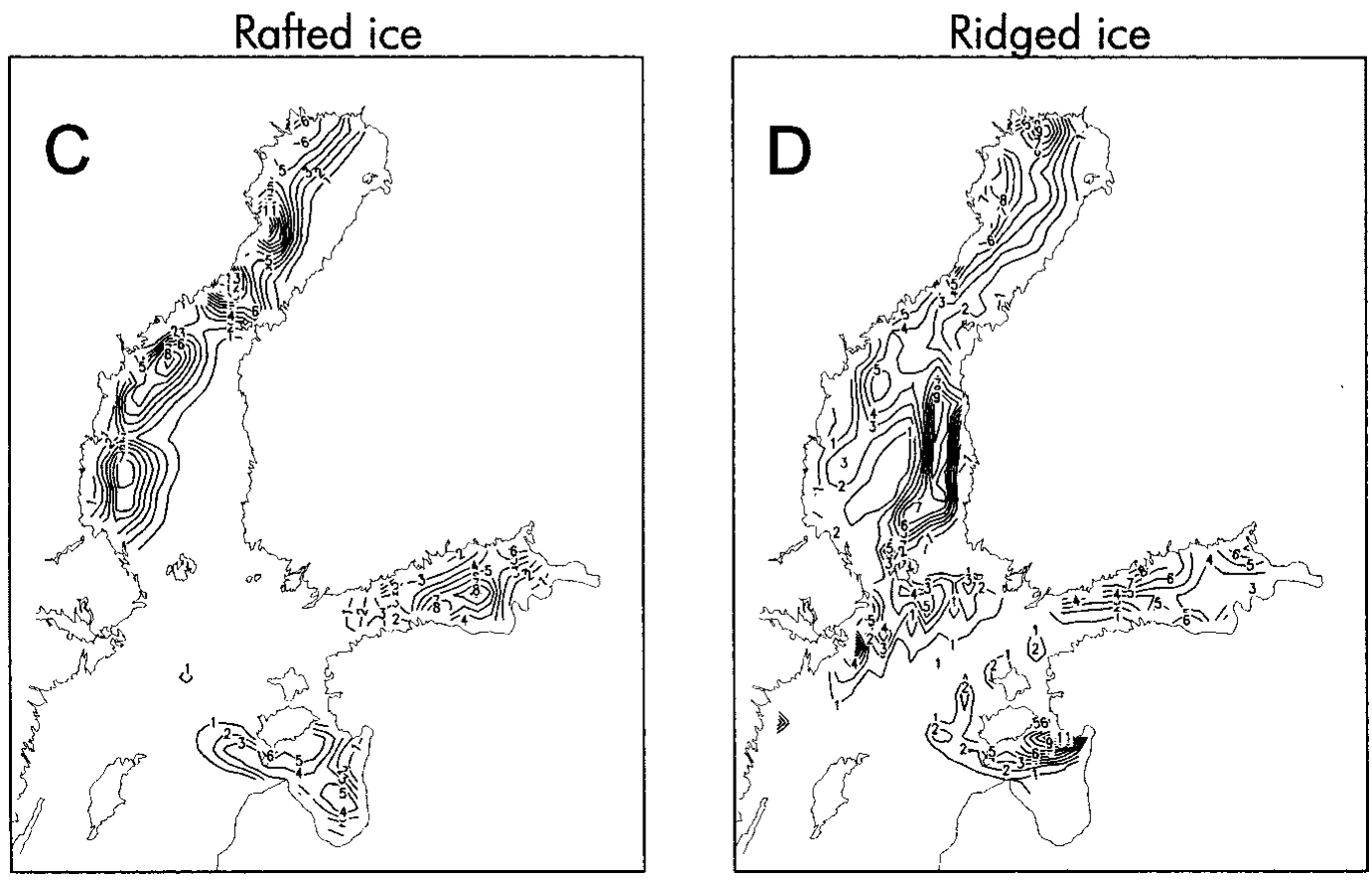

Fig. 7. (a) Observed ice situation, and modelled mean ice thickness of (b) lead, (c) rafted and (d) ridged ice on 3 March 1994.

Units are $\mathrm{cm}$.

ridged-ice production rate. After the stormy periods in January 1994, the model produces almost no deformed ice during mid-winter. March and April are again times of deformed-ice production because of the higher mobility of the ice pack.

Figure 9 shows the response of the model to strong winds. During the period 5-7 March a strong southwesterly wind prevailed, driving the ice pack northwards and causing ridging along the northern coasts of the basin, and opening of the ice pack in the southern regions. A north-south transect of the modelled level- and ridged-ice thickness before and after the event gives an estimate of the ridging processes. The central pack moved as a rigid body without significant deformations. It was advected northward and experienced deformation when it hit the coastline. The deformation-zone width was about $50 \mathrm{~km}$ in the Bay of Bothnia and $100 \mathrm{~km}$ in the Bothian Sea. The ridged-ice thickness was about 5-10 cm at the beginning, but after the strong wind events the amount of ridged ice doubled. The ratio of the ridged-ice to level-ice mass increased from 0.15 to 0.4 in the ridged regions of the Bay of Bothnia.

Although the response of the model is realistic, it overestimates the deformation during this period. According to the ice-velocity information from European Remote-sensing Satellite synthetic-aperture radar (ERS-1 SAR) images (Leppäranta and others, 1998), deformation occurred in even narrower coastal zones than predicted by the model. Also, the modelled ice velocities are higher than observed, leading to larger deformation rates. Figures 5 and 8 show that the model simulated rather immobile conditions 


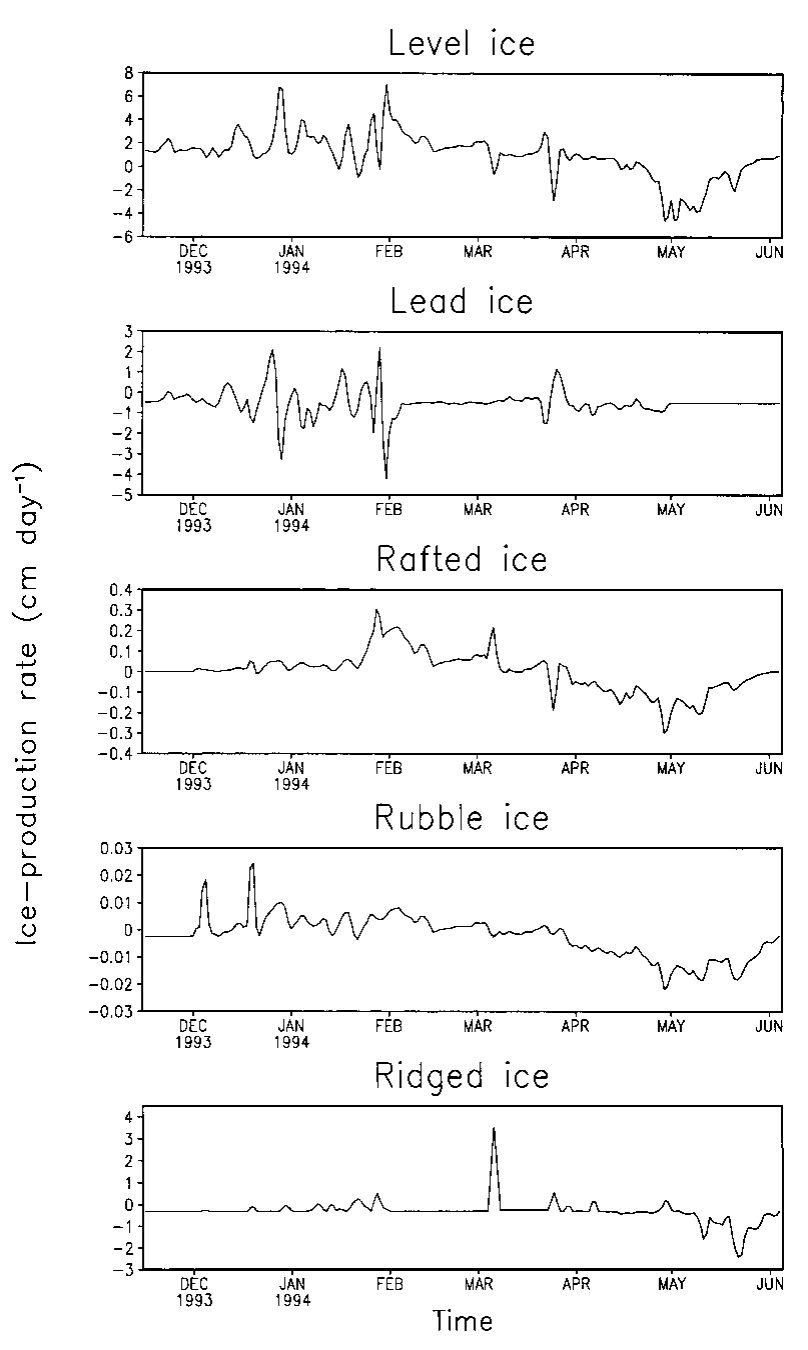

Fig. 8. Ice-production rates for level, lead, rafted, rubble and ridged ice in the Bay of Bothnia.

during the whole of the month before the storm, although some deformation was observed during that time. Thus the model calculates too high an internal stress for the ice pack when mild or moderate forcing is acting and the model remains in the immobile mode. When strong forcing is applied, the modelled ice pack begins to move, but with too high a velocity. Also the plastic ice model broadens the deformation zone.

The ratio of the deformed ice to the total ice mass is of particular interest because it directly expresses the accumulation and significance of the deformed ice. Locally, the ratio can be 1 , and on a large scale it is about 1:3 (Lewis and others,

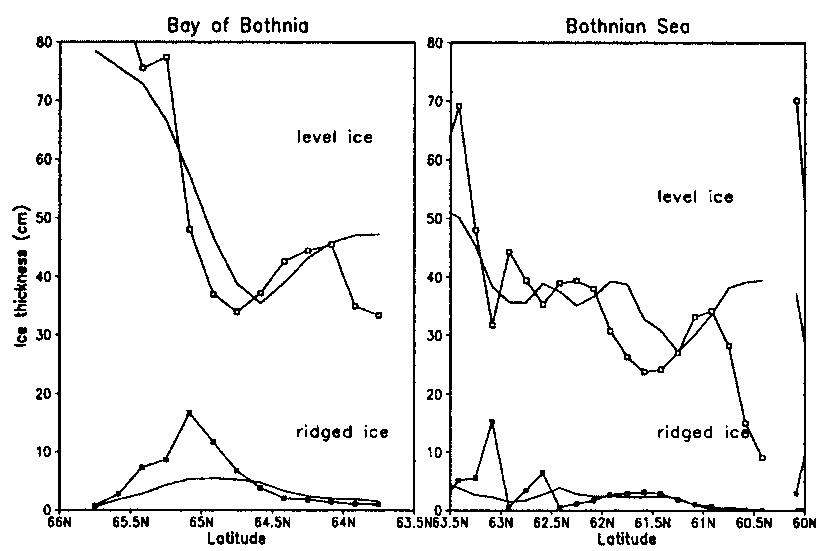

Fig. 9. Transect of the mean level-and ridged-ice thickness on 1 March 1994 (solid line) and 10 March 1994 (line with symbols).
1993). Figure 10 shows modelled time series of the deformedice fraction integrated over the Bay of Bothnia, the Bothnian Sea and the northern Baltic proper and the Gulf of Finland. The different characteristics of the basins and an increase in the deformed-ice mass over time are evident. There are two phases of deformation in the Bay of Bothnia. In early winter the deformed-ice fraction increases to 0.2. During mid-winter it slightly decreases because of the faster thermodynamic growth rate of undeformed ice. The ratio increases during spring due to new deformations and the melting of the undeformed ice. Finally, there is only deformed ice left. This seasonal evolution of the deformed-ice fraction is typical for the Baltic. All observations at the end of the ice season show that the deformed ice melts later than undeformed ice. In the Arctic the situation seems to be reversed (Wadhams, 1992; Flato and Hibler, 1995).

Finally, the mean ice thicknesses of the lead, rafted, rubble and ridged ice during winter are shown in Figure 11 which indicates the importance of the coastal region in the sea-ice mass balance. Coastal regions are the areas where thin lead ice is continuously produced under divergent conditions and is redistributed into the deformed ice classed during convergent ice motion. The ice mass is larger in the coastal regions than in the open sea and in the fast-ice areas of the basins.

Model results are not very sensitive to the model parameters. The total undeformed- and deformed-ice masses are controlled by the surface fluxes, the ice-velocity divergence and the redistribution functions. The redistribution functions of the present model utilize a well-established dependence of the deformation processes on the undeformed-ice thickness and compactness. Some uncertainties exist in the modelled ice velocities because of the constant ice strength used in the model. The model tends to underestimate the production of deformed-ice mass during mid-winter, and to overestimate the deformation during stormy periods. Determination of

\section{Bay of Bothnia}

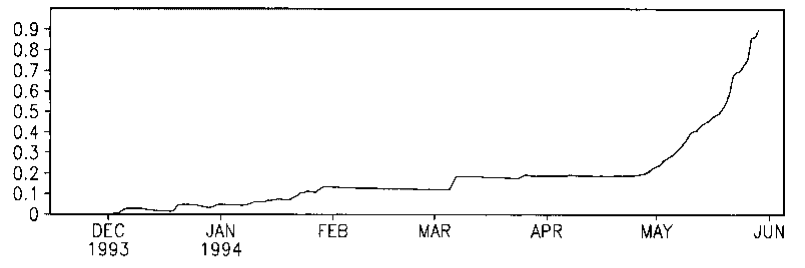

Bothnian Sea
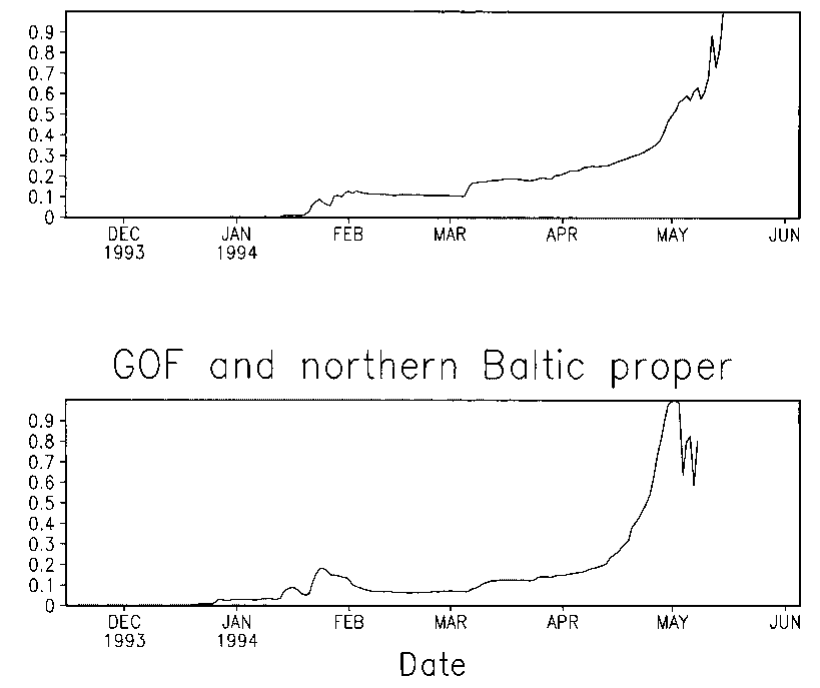

Fig. 10. Ratio of deformed ice to total ice mass. 


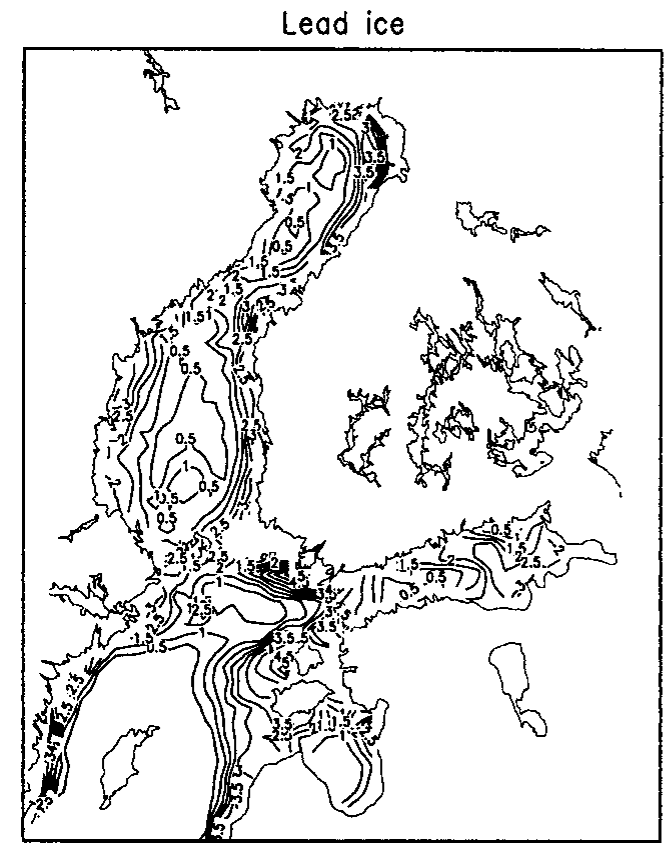

Rubble ice

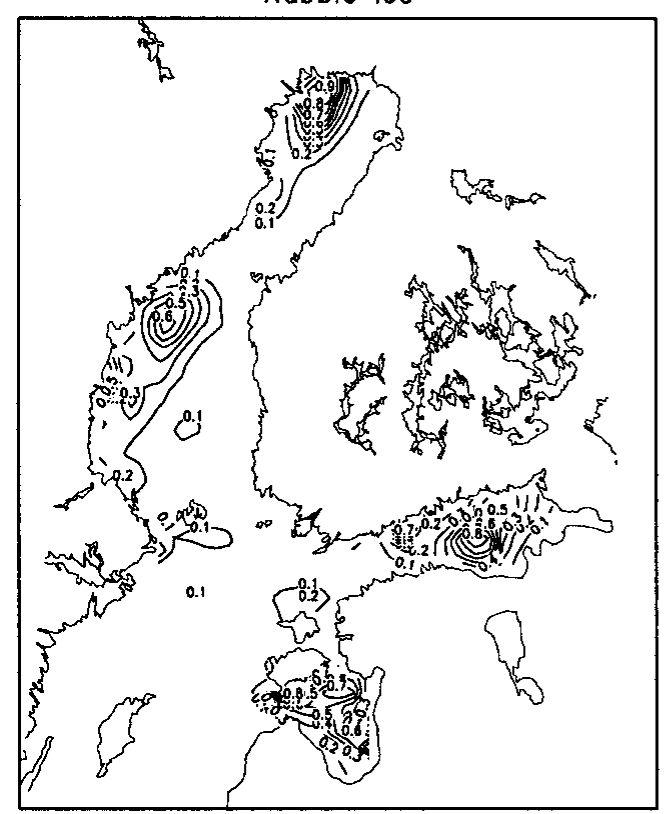

Rafted ice

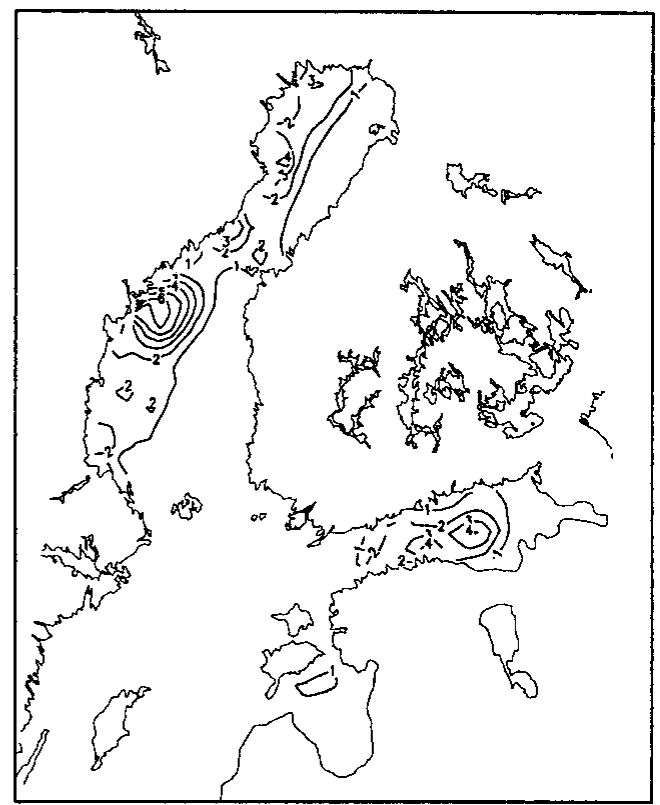

Ridged ice

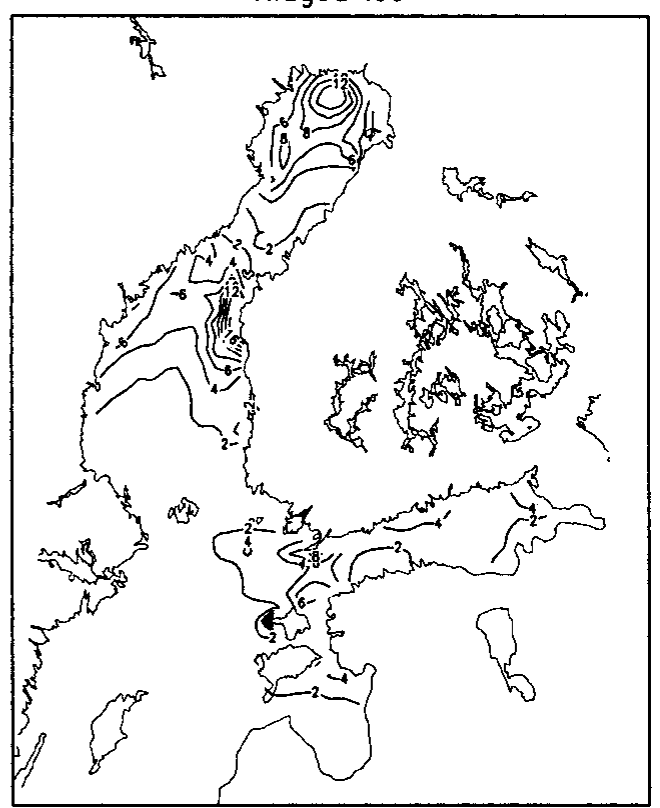

Fig. 11. Mean lead, rafted, rubble and ridged model ice thickness in the Baltic Sea, winter 1994. Units are cm.

the growth rate of ridged-ice compactness (Equation (26)) contains some uncertainties because of the simple geometric model and the empirical functions used in the model.

\section{CONCLUSIONS}

Existing ice models are not good at resolving when, where and how much deformed ice is generated on a seasonal scale. The only exceptions are the Harder and Lemke (1994) model, which is an extension of the Hibler (1979) two-level model, and the Flato and Hibler (1995) model, which solves the ice-thickness distribution function separately for the undeformed and deformed ice. This paper presents a simplified approach based on physical ice classes.

An ice-thickness redistribution model has been formulated where the pack ice is composed of open water, two different types of undeformed ice, and rafted ice, rubble ice and ridged ice. The benefits of the physically based ice-thickness distri- bution model are that ice classes are prognostic variables, and inherent thermodynamic growth and decay are calculated for each ice class. The main advantage of the model is that it separates thermally and mechanically produced ice.

Numerical experiments for the Baltic Sea show that the model produces a realistic seasonal evolution of the pack ice. Both sub-basin and inter-basin ice characteristics were realized by the model. Deformed-ice production is a stepwise process related to storm activity. About ten active deformation episodes were modelled in the Baltic for winter 1994. Most of the deformation was produced in the coastal zone, which is also an important region for thermodynamically produced ice because of the ice growth in leads. Modelled mechanical growth rates of ice were $0.5-3 \mathrm{~cm} \mathrm{~d}^{-1}$ on a basin scale, which is close to the thermodynamic ice-production rates. The deformed-ice fraction increased during the season. In early and mid-winter it was about 0.2 , and during spring it increases to $0.5-1.0$ due to new deformations and the melting of the undeformed ice. 
The ice-class approach gives more information on the surface properties of the ice pack than the widely used twolevel model of Hibler (1979). The ice concentration, surface temperature, albedo and surface roughness are the primary factors governing the atmospheric and oceanic boundary layers, and since these parameters are explicitly resolved for each ice class, it allows detailed calculation of the exchange of heat and momentum between the atmosphere/ ice/ocean interfaces.

In the near future it will be possible to make much greater use of remote-sensing and model data for sea-ice research, since remote-sensing ice-classification algorithms now also resolve ice classes. Hence, remote-sensing data can be used to verify the redistribution functions, and can even be used for data assimilation into the ice model.

\section{ACKNOWLEDGEMENTS}

I am grateful to M. Leppäranta for discussions and guidance relating to this study. Comments by J. Tuhkuri, R. Timmermann and an anonymous referee were very helpful in improving the manuscript. The Swedish Meteorological and Hydrological Institute is thanked for providing the meteorological forcing data, and the ice-concentration data were provided by the Earth Observing System Distributed Active Archive Center at the U.S. National Snow and Ice Data Center, University of Colorado, Boulder. This work was supported by the Baltic Sea System Study of the European Commission Marine Science and Technology program MAST III, under contract MAS3-CT96-0058.

\section{REFERENGES}

Arbetter, T. E., J. A. Curry and J. A. Maslanik. In press. Effects of rheology and ice thickness distribution in a dynamic-thermodynamic sea ice model. 7. Phys. Oceanogr.

Bumke, K., U. Karger, L. Hasse and K. Niekamp. 1998. Evaporation over the Baltic Sea as an example of a semi-enclosed sea. Contrib. Atmos. Phys., 71 (2), 249-261.

Finnish Institute of Marine Research (FIMR). 1994. Baltic Sea ice charts. Helsinki, Finnish Institute of Marine Research.

Flato, G. M. and W. D. Hibler, III. 1995. Ridging and strength in modeling the thickness distribution of Arctic sea ice. 7. Geophys. Res., $\mathbf{1 0 0}(\mathrm{C} 9)$, $18,611-18,626$.

Gray, J. M. N. T. and P. D. Killworth. 1996. Sea ice ridging schemes. F. Phys. Oceanogr., 26(11), 2420-2428.

Gray, J. M. N. T. and L. W. Morland. 1994. A two-dimensional model for the dynamics of sea ice. Philos. Trans. R. Soc. London, Ser. A, 347(1682), 219-290.

Guest, P. S. and K. L. Davidson. 1991. The aerodynamic roughness of different types of sea ice. 7. Geophys. Res., 96(C3), 4709-4721.

Haapala, J. and P. Alenius. 1994. Temperature and salinity statistics for the northern Baltic Sea, 1961-69. Finn. Mar. Res. 262, 51-121.

Haapala, J. and M. Leppäranta. 1996. Simulating the Baltic Sea ice season with a coupled ice--ocean model. Tellus, 48A(5), 622-643.

Harder, M. and P. Lemke. 1994. Modelling the extent of sea ice ridging in the Weddell Sea. In Johannessen, O. M., R. D. Muench and J. E. Overland, eds. The polar oceans and their role in shaping the global environment: the Nansen Centennial volume. Washington, DC, American Geophysical Union, 187-197. (Geophysical Monograph 85.)

Hibler, W. D., III. 1979. A dynamic thermodynamic sea ice model. F. Phys. Oceanogr., 9(7), 815-846.

Hibler, W. D., III. 1980. Modeling a variable thickness sea ice cover. Mon. Weather Rev., 108(12), 1943-1973.

Hopkins, M. A. 1998. Four stages of pressure ridging. 7. Geophys. Res., $\mathbf{1 0 3}(\mathrm{C} 10), 21,883-21,891$.

Hopkins, M. A., J. Tuhkuri and M. Lensu. 1999. Rafting and ridging of thin ice sheets. f. Geophys. Res., 104(C6), 13,605-13,613.
Kankaanpää, P. 1991. Distribution, morphology and structure of sea ice pressure ridges in the Baltic Sea. Fennia, 175(2), 139-240.

Lehmann, A. and H. H. Hinrichsen. In press. On the thermohaline variability of the Baltic Sea. 7. Mar. Syst.

Lensu, M. 1998. Laser profilometer measurements in the Bay of Bothnia during the ZIP-97 experiment. Otaniemi, Helsinki University of Technology. Ship Laboratory. (Report Series M-232.)

Leppäranta, M. 1981a. An ice drift model for the Baltic Sea. Tellus, 33(6), 583-596.

Leppäranta, M. 1981b. On the structure and mechanics of pack ice in the Bothnian Bay. Finn. Mar. Res. 248, 3-86.

Leppäranta, M. and R. Hakala. 1992. The structure and strength of firstyear ice ridges in the Baltic Sea. Cold Reg. Sci. Technol., 20(3), 295-311.

Leppäranta, M., Yan Sun and J. Haapala. 1998. Comparisons of sea-ice velocity fields from ERS-1 SAR and a dynamic model. F. Glaciol., 44(147), 248-262.

Lewis, J. E., M. Leppäranta and H. B. Granberg. 1993. Statistical properties of sea ice surface topography in the Baltic Sea. Tellus, 45A(2), 127-142.

National Snow and Ice Data Center (NSIDC). 1994. Nimbus-7 SMMR polar radiances and Arctic and Antarctic sea ice concentrations on CD-ROM: user's guide. Boulder, CO, University of Colorado. Cooperative Institute for Research in Environmental Sciences. National Snow and Ice Data Center. (Special Publication 3.)

Omstedt, A. 1998. Freezing estuaries and semi-enclosed basins. In Leppäranta, M., ed. Physics of ice-covered seas. Vol. 2. Helsinki, University of Helsinki. Department of Geophysics, 483-516.

Palosuo, E. 1974. The formation and structure of ice ridges in the Baltic. Helsinki, University of Helsinki. Finnish Institute of Marine Research. Winter Navigation Research Board. (Research Report 12.)

Parmerter, R. R. 1975. A model of simple rafting in sea ice. 7. Geophys. Res., $80(15), 1948-1952$.

Schrum, C. 1997. An ice/ocean model for North and Baltic Sea. In Özsoy, E. and A. Mikaelyna, eds. Sensitivity of the North Sea, Baltic Sea and Black Sea to anthropogenic and climatic changes. Dordrecht, Kluwer Academic Publishers, 311-325. (NATO ASI Series 27.)

Schulkes, R. M. S. M. 1995. A note on the evolution equations for the area fraction and the thickness of a floating ice cover. F. Geophys. Res., $100(\mathrm{C} 3)$, $5021-5024$

Seifert, T. and B. Kayser. 1995. A high resolution spherical grid topography of the Baltic Sea. Warnemünde, Institut für Ostseeforschung, 74-88. (Marine Science Reports 9.)

Seinä, A., H. Grönvall, S. Kalliosaari and J. Vainio. 1996. Ice seasons 1991-1995 along the Finnish coast. Meri, 27, 3-77.

Semtner, A. J., Jr. 1976. A model for the thermodynamic growth of sea ice in numerical investigations of climate. 7. Phys. Oceanogr., 6 (5), 379-389.

Shinohara, Y. 1990. A redistribution function applicable to a dynamic sea ice model. 7. Geophys. Res., 95(C8), 13,423-13,431.

Squire, V. A. 1998. The marginal ice zone. In Leppäranta, M., ed. Physics of ice-covered seas. Vol. 1. Helsinki, University of Helsinki. Department of Geophysics, 381-446.

Steiner, N., M. Harder and P. Lemke. 1999. Sea ice roughness and drag coefficients in a dynamic-thermodynamic sea ice model for the Arctic. Tellus, 51A, 964-978.

Stern, H. L., D. A. Rothrock and R. Kwok. 1995. Open water production in Arctic sea ice: satellite measurements and model parameterization. $\mathcal{F}$. Geophys. Res., 100 (C10), 20,601-20,612.

Thorndike, A. S., D. A. Rothrock, G. A. Maykut and R. Colony. 1975. The thickness distribution of sea ice. F. Geophys. Res., 80(33), 4501-4513.

Timco, G.W. and R. P. Burden. 1997. An analysis of the shapes of sea ice ridges. Cold Reg. Sci. Technol., 25(1), 65-77.

Tremblay, L. -B. and L. A. Mysak. 1997. The possible effects of including ridge-related roughness in air-ice drag parameterization: a sensitivity study. Ann. Glaciol., 25, 22-25.

Tuhkuri, J. and M. Lensu. 1998. Ice tank tests on ridging of non-uniform ice sheets. Espoo, Helsinki University of Technology. Ship Laboratory. (Report M-236.)

Vihma, T. 1995. Sub-grid parameterization of surface heat and momentum fluxes over polar oceans. F. Geophys. Res., 100 (C11), 22,625-22,646.

Wadhams, P. 1992. Sea ice thickness distribution in the Greenland Sea and Eurasian Basin. 7. Geophys. Res., 97(C4), 5331-5348.

World Meteorological Organization (WMO). 1970. WMO sea-ice nomenclature: terminology, codes and illustrated glossary. Geneva, Secretariat of the World Meteorological Organization. (WMO/OMM/BMO Report 259, TP 145.)

Zhang, Z. and M. Leppäranta. 1995. Modeling the influence of ice on sea level variations in the Baltic Sea. Geophysica, 31 (2), 31-45. 